\title{
Oxidized Nanocarbons-Tripeptide Supramolecular Hydrogels: Shape Matters!
}

\author{
Daniel Iglesias, ${ }^{\dagger}$ Manuel Melle-Franco, ${ }^{\ddagger}$ Marina Kurbasic, ${ }^{\dagger}$ Michele Melchionna, ${ }^{\dagger}$ (๖ Michela Abrami, ${ }^{\S}$

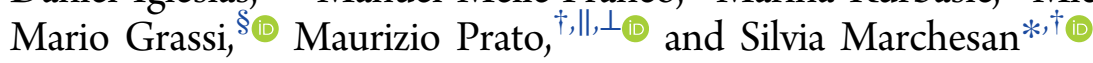

${ }^{\dagger}$ Dipartimento di Scienze Chimiche e Farmaceutiche, Università di Trieste, Via L. Giorgieri 1, 34127 Trieste, Italy

${ }^{\ddagger}$ CICECO, University of Aveiro, 3810-193 Aveiro, Portugal

${ }^{\S}$ Dipartimento di Ingegneria e Architettura, Università di Trieste, V. Valerio 6/1, 34127 Trieste, Italy

"Carbon Nanobiotechnology Laboratory, CIC biomaGUNE, Paseo de Miramón 182, 20009 Donostia-San Sebastian, Spain

${ }^{\perp}$ Basque Foundation for Science, Ikerbasque, Bilbao 48013, Spain

\section{Supporting Information}

\begin{abstract}
Short peptide hydrogels are attractive biomaterials but typically suffer from limited mechanical properties. Inclusion of other nanomaterials can serve the dual purpose of hydrogel reinforcement and of conferring additional physicochemical properties (e.g., self-healing, conductivity), as long as they do not hamper peptide self-assembly. In particular, nanocarbons are ideal candidates, and their physicochemical properties have demonstrated great potential in nanocarbon-polymer gel biomaterials for tissue engineering or drug delivery. Recently, increasing interest in supramolecular hydrogels drove research also on their enhancement with nanocarbons. However, little is known on the effect of

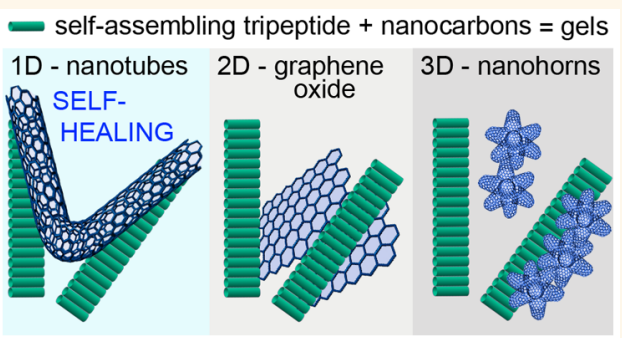
nanocarbon morphology on the self-assembly of short peptides, which are among the most popular hydrogel building blocks. In this work, three different oxidized nanocarbons (i.e., carbon nanotube or CNT as 1D material, graphene oxide sheet or GO as 2D material, and carbon nanohorn or $\mathrm{CNH}$ as $3 \mathrm{D}$ material) were evaluated for their effects on the selfassembly of the unprotected tripeptide Leu- ${ }^{\mathrm{D}} \mathrm{Phe}-{ }^{\mathrm{D}} \mathrm{Phe}$ at physiological conditions. Supramolecular hydrogels were obtained in all cases, and viscoelastic properties were clearly affected by the nanocarbons, which increased stiffness and resistance to applied stress. Notably, self-healing behavior was observed only in the case of CNTs. Tripeptide-nanotube interaction was noted already in solution prior to self-assembly, with the tripeptide acting as a dispersing agent in phosphate buffer. Experimental and in silico investigation of the interaction between peptide and CNTs suggests that the latter acts as nucleation templates for self-assembly and reassembly. Overall, we provide useful insights for the future design of composite biomaterials with acquired properties.
\end{abstract}

KEYWORDS: carbon nanohorn, carbon nanotube, graphene oxide, hydrogel, peptide, self-assembly

hort peptides are attractive candidates for supramolecular hydrogel biomaterials ${ }^{1}$ in light of their inherent biocompatibility and biodegradability, ease of preparation, ${ }^{2}$ ability to encode biological messages, ${ }^{3}$ or to exert a biological function (e.g., induce cell death on demand, ${ }^{4}$ adjuvate immune response to vaccines, ${ }^{5}$ etc.). A popular approach consists of derivatizing amino acids or short peptides with aromatic $\mathrm{N}$-capping groups that template self-assembly. ${ }^{6,7}$ However, for biological applications, unprotected peptides as short as three amino acids are preferable, although their supramolecular behavior is far more challenging to predict. ${ }^{8}$ Indeed, only a few unprotected tripeptide gelators have been reported thus far, mainly containing the convenient Phe-Phe motif. ${ }^{9}$ The unreported hydrophobic Leu- ${ }^{\mathrm{D}} \mathrm{Phe}-{ }^{\mathrm{D}} \mathrm{Phe}$ was chosen for this study, since it is expected to be an attractive gelator based on its enantiomer ability to form hydrogel biomaterials that did not elicit cytotoxicity in vitro. ${ }^{10}$
However, unprotected tripeptide hydrogels typically suffer from limited mechanical properties, since they do not withstand high stresses and their moduli are often lower than $10 \mathrm{kPa}$. In line of principle, hydrogel reinforcement could be achieved by inclusion of a nanocarbon, which may also add other interesting properties, such as NIR responsiveness or conductivity to achieve responsive materials. ${ }^{11-13}$ To this end, appropriate nanocarbon functionalization is a convenient approach to assist dispersibility in water and interaction with other chemical components. ${ }^{14}$ Peptide/protein-nanocarbon systems have indeed attracted a lot of interest in light of their complementary properties for biological applications, although they are

Received: February 12, 2018

Accepted: May 22, 2018

Published: May 22, 2018 
remarkably difficult to design and control. ${ }^{15,16}$ Peptides can be covalently bound to the nanocarbon to assist with the formation of hybrid materials, and/or they can engage in noncovalent interactions, such as $\pi-\pi$ (e.g., phenylalanine) or cation $-\pi$ (e.g., arginine or lysine), to assist also with nanocarbon dispersion in water. ${ }^{15}$ Multicomponent nanostructured hydrogels of this kind are indeed at the forefront of research in regenerative medicine, especially of the heart ${ }^{17}$ and nerve tissue. ${ }^{18}$

In the case of nanocarbon and short-peptide aqueous systems, only a very few isolated examples have been described in the literature, and general guiding principles for design have not emerged yet. Hydrogels were reported for Fmoc-Phe and oxidized single-wall carbon nanotubes (SWCNTs), ${ }^{19}$ and Fmoc-Phe-Asp or Fmoc-Tyr-Asp and reduced graphene oxide (RGO).$^{20}$ In all cases, stiffer materials were obtained upon inclusion of the nanocarbon. In a different approach, mechanochemical forces were exploited to disperse and gel pristine MWCNTs or graphite in water, by using an amino acid derivative bearing: two Fmoc units, to establish $\pi-\pi$ interactions with the nanocarbon, and a $\mathrm{C}-\mathrm{C}$ double bond, to define molecular geometry. ${ }^{21}$ Therefore, it would appear plausible to include nanocarbons in a supramolecular hydrogel formed by an unprotected tripeptide, especially if bearing aromatic amino acids that may engage in $\pi-\pi$ interactions with the $\mathrm{sp}^{2}$ lattice. Boc-protected $\beta$ - or $\gamma$-diphenylalanine was shown to favorably engage with suitably functionalized MWCNTs in the formation of dendrimer nanostructures, while the unprotected peptide analogues did not self-assemble, highlighting dramatic differences between protected and unprotected peptides. ${ }^{22}$

To date, there is no report on hydrogels obtained from an unprotected tripeptide and a nanocarbon, and no study on the morphological effects related to different nanocarbon structures on such systems. This study aims to fill the gap, by comparing supramolecular systems composed of Leu- ${ }^{\mathrm{D}}$ Phe- ${ }^{\mathrm{D}}$ Phe tripeptide and one of the following: carbon nanotubes as 1D structure, graphene oxide sheets as $2 \mathrm{D}$ structure, and carbon nanohorns as $3 \mathrm{D}$ structure. Each nanostructure was first oxidized, since it is well-known that functionalization methods, which shorten and render CNTs hydrophilic, will reduce $\mathrm{CNT}$ aggregation and ameliorate their biocompatibility. ${ }^{23}$ Therefore, the first step consisted of fine-tuning oxidation conditions for each nanocarbon based on their different reactivity to (1) achieve comparable levels of oxidation, as evaluated by thermogravimetric analysis (TGA) and (2) significantly shorten CNTs. Next, we evaluated each peptide-nanocarbon system in phosphate buffer prior to, during, and after self-assembly into hydrogels at physiological conditions. Each system was analyzed by means of Raman and attenuated total reflection infrared (ATR-IR) spectroscopy, circular dichroism (CD), oscillatory rheometry, and transmission electron microscopy (TEM). Although reinforced hydrogels were obtained in all cases, carbon nanohorns showed a marked tendency toward segregation resulting in a non-homogeneous system. On the contrary, hydrogels with GO or oxidized CNTs benefited from interactions between the nanocarbon and the peptide fibers. In particular, CNTs conferred self-healing ability to the hydrogels, and in silico data provided useful insights into peptide-CNT interaction.

\section{RESULTS AND DISCUSSION}

Peptide Gelator. The hydrophobic heterochiral tripeptide ${ }^{\mathrm{L}}$ Leu- ${ }^{\mathrm{D}}$ Phe- ${ }^{\mathrm{D}}$ Phe (Figure 1A) was prepared by Fmoc-based
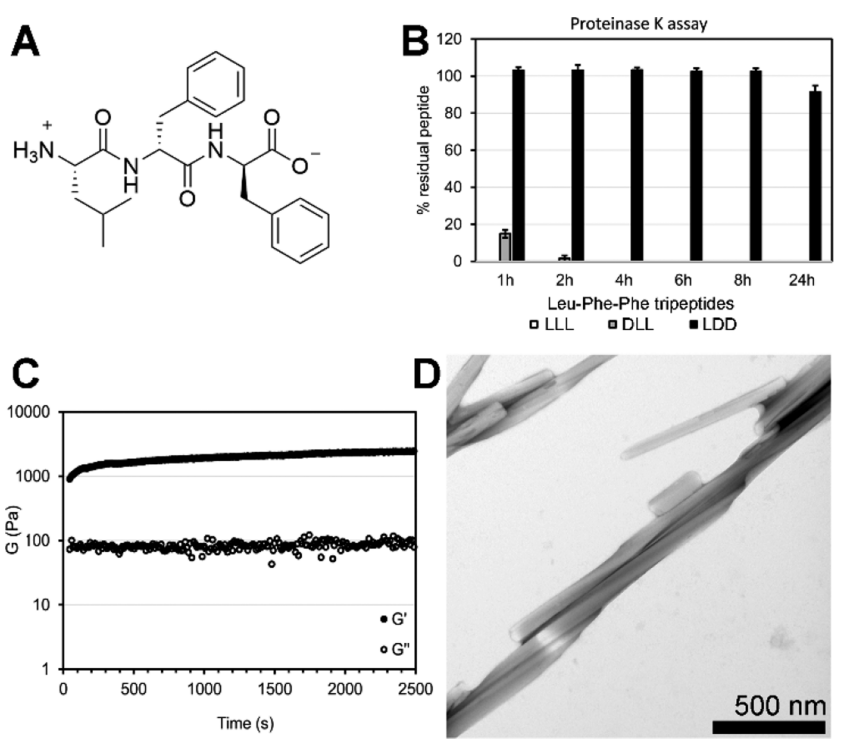

Figure 1. (A) Chemical structure of Leu- ${ }^{\mathrm{D}}$ Phe- ${ }^{\mathrm{D}}$ Phe tripeptide gelator. (B) Proteinase $\mathrm{K}$ hydrolysis assay. (C) Time sweep oscillatory rheometry data. (D) TEM micrograph of peptide fibers.

solid-phase peptide synthesis, purified by reversed-phase HPLC, and freeze-dried, leading to a fluffy white powder for the pure compound as confirmed by LC-MS, ${ }^{1} \mathrm{H} \mathrm{NMR}$, and ${ }^{13} \mathrm{C}$ NMR data (see Supporting Information Figures S2-S5). Presence of two D-amino acids increased its resistance to protease hydrolysis relative to other stereoisomers, to a far greater extent than previously observed for similar sequences. ${ }^{24}$ ${ }^{\mathrm{L}}$ Leu- ${ }^{\mathrm{L}} \mathrm{Phe}-{ }^{\mathrm{L}} \mathrm{Phe}$ and ${ }^{\mathrm{D}}$ Leu- $-{ }^{\mathrm{L}} \mathrm{Phe}-{ }^{\mathrm{L}} \mathrm{Phe}$ were both completely digested during the first $1-2 \mathrm{~h}$, while over $90 \%$ of ${ }^{\mathrm{L}}$ Leu- ${ }^{\mathrm{D}}$ Phe- ${ }^{\mathrm{D}}$ Phe was still present after $24 \mathrm{~h}$ in solution with a large excess of proteinase K (Figure 1B).

The gelator design was based on our previous studies, ${ }^{25}$ and indeed hydrogels were obtained at physiological conditions upon application of a $\mathrm{pH}$ trigger. Briefly, the peptide dissolved as an anion at alkaline $\mathrm{pH}$ thanks to the repulsion between the charged molecules. Addition of an equal amount of mildly acidic buffer led to rapid hydrogelation at $\mathrm{pH} 7.4$, as confirmed by the vial inversion test and oscillatory rheometry. A frequency sweep test was performed to evaluate the gel nature, as gels should display an elastic modulus $\left(G^{\prime}\right)$ higher than the viscous modulus $\left(G^{\prime \prime}\right)$, with both moduli being independent of the oscillation frequency. In this manner, the minimum gelling concentration (mgc) was determined to be $0.5 \mathrm{mg} \mathrm{mL}$ $(0.05 \% \mathrm{w} / \mathrm{v}$ or $1.17 \mathrm{mM}$, see Figure S6). However, gels at mgc were weak (i.e., $G^{\prime} \sim 0.4 \mathrm{kPa}$ ), thus $2.5 \mathrm{mg} \mathrm{mL}^{-1}$ of ${ }^{\mathrm{L}} \mathrm{Leu}-{ }^{\mathrm{D}} \mathrm{Phe}-{ }^{\mathrm{D}} \mathrm{Phe}$ was chosen as an ideal concentration for further tests, since it yielded hydrogels with more applicable mechanical properties (i.e., $G^{\prime} 2 \mathrm{kPa}$ after $30 \mathrm{~min}$ of selfassembly). The hydrogel formed too quickly to visualize the sol-to-gel transition, with its viscoelastic moduli rising rapidly during the first 30 min until they reached a plateau (Figure 1C), corresponding to complete self-assembly into fibrils. Further hierarchical organization of fibrils into fibers and bundles as thick as hundreds of nanometers slowly occurred during the following hours, as confirmed by TEM (Figure 1D). 
Self-assembled peptide fibers were analyzed also by Raman microspectroscopy. This technique was previously used to study Phe-Phe nano and microtubes, ${ }^{26}$ but it is not widely applied due to the challenging detection of the weak Raman signals of short peptide self-assemblies. The two Raman-active modes related to the aromatic ring at 1003 and $1037 \mathrm{~cm}^{-1}$ were clearly visible, with the former being the most intense signal, which was chosen to map an image of the fiber bundle using Raman microscopy (Figure 2). The other two aromatic signals
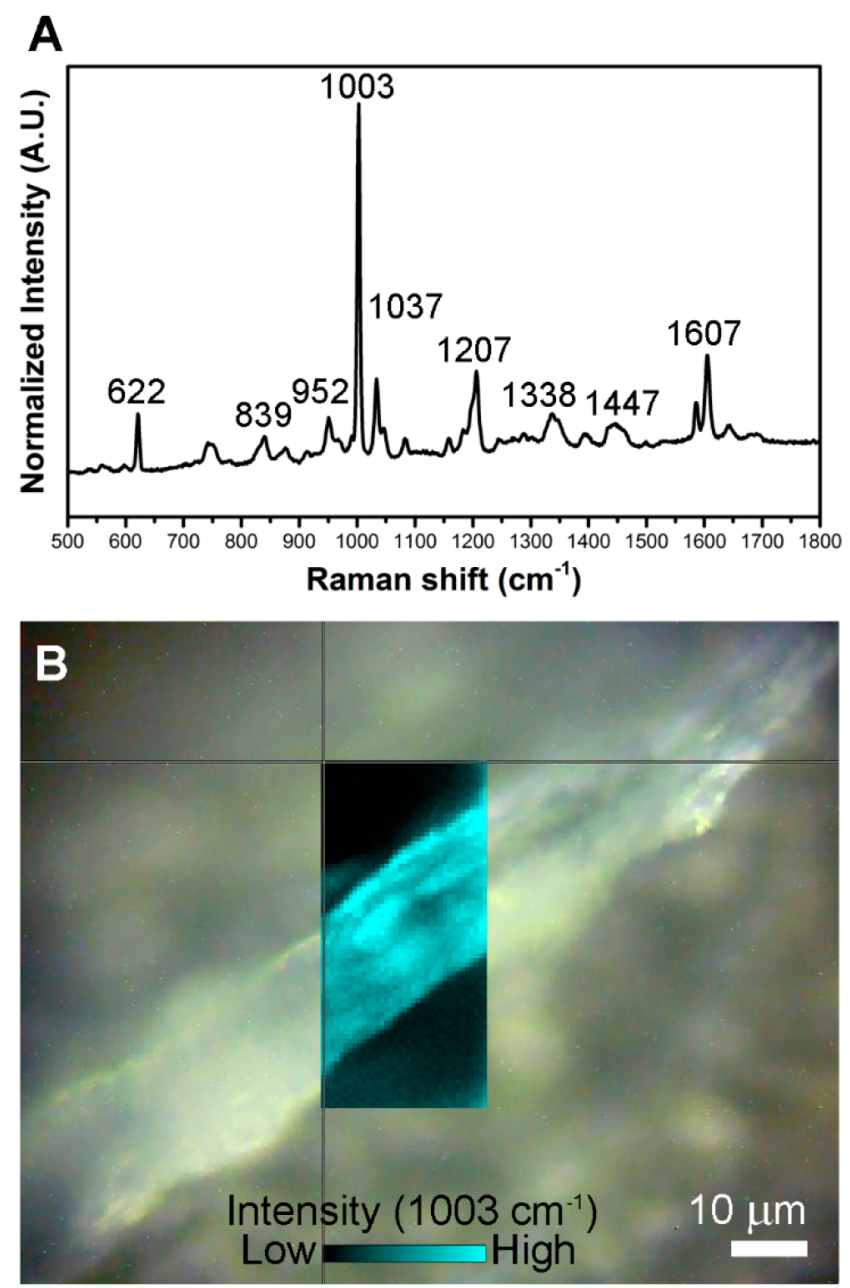

Figure 2. (A) Raman spectrum of ${ }^{\mathrm{D}}$ Leu-Phe-Phe hydrogel. (B) Raman spectro-microscopy mapping image of a fiber bundle (normalized intensity at $1003 \mathrm{~cm}^{-1}$ in cyan, $102-699$ relative counts).

at 1587 and $1607 \mathrm{~cm}^{-1}$ were also visible. In the amide I region, the major peak at $1641 \mathrm{~cm}^{-1}$ arises from the $\mathrm{C}=\mathrm{O}$ stretching, while 1682 and $1691 \mathrm{~cm}^{-1}$ indicate hydrogen bonding at both the $\mathrm{C}=\mathrm{O}$ and $\mathrm{N}-\mathrm{H}$ components of the peptide bond, ${ }^{26}$ as expected for $\beta$-stacks. ${ }^{25}$ The weak signal at $1246 \mathrm{~cm}^{-1}$ was assigned to the amide III, and it is also characteristic of the hydrogen-bonding pattern; while signals at 1270 and 1288 $\mathrm{cm}^{-1}$ likely correspond to mixed vibrational modes of $\mathrm{C}_{\beta}-\mathrm{H}$ bending, $\mathrm{C}_{\alpha}-\mathrm{H}$ out-of-plane bending, $\mathrm{N}-\mathrm{H}$ in-plane bending, and $\mathrm{C}_{\alpha}-\mathrm{C}_{\beta}$ stretching. Overall, the Raman spectrum suggests differences relative to the dipeptide Phe-Phe packing into nanotubes, especially due to the involvement of the $\mathrm{C}=\mathrm{O}$ in the hydrogen-bonding pattern. ${ }^{26}$
Peptide-Nanocarbon Hydrogels. To probe self-assembly in the presence of different nanocarbons, which are notoriously hydrophobic, these were first oxidized to reduce their aggregation propensity and achieve water dispersibility. To this end, functionalization protocols were optimized for each nanostructure (i.e., $\mathrm{CNT}, \mathrm{G}, \mathrm{CNH}$ ), whose reactivity is strongly affected by morphological parameters, such as curvature, number of graphitic layers, etc. As a result, each nanocarbon was oxidized (Figure $3 \mathrm{~A}$ ) to the same extent as monitored by

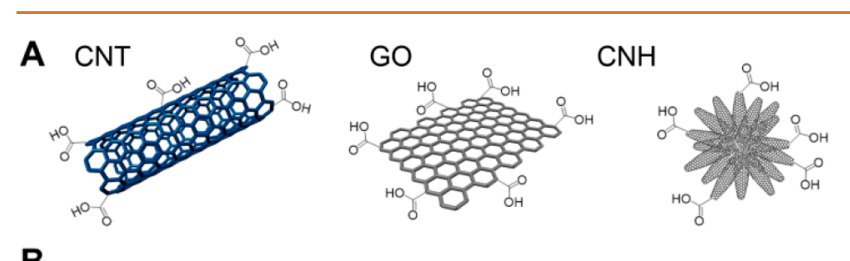

B

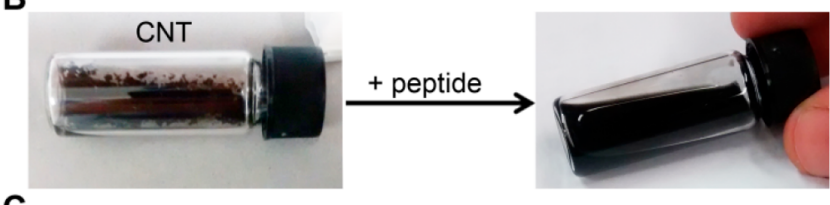

C
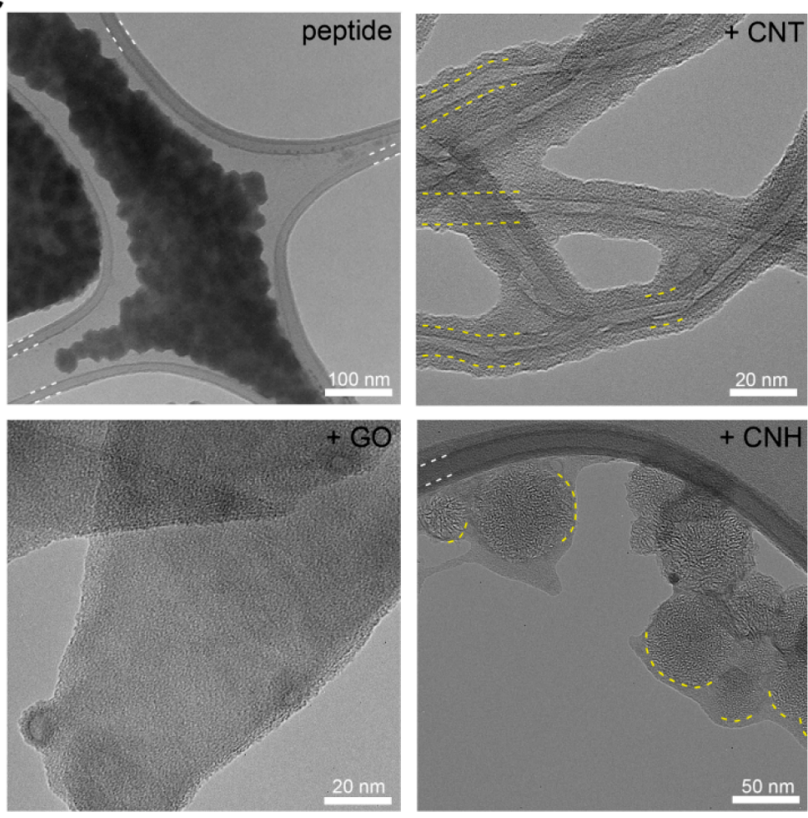

Figure 3. (A) Oxidized nanocarbons used in this study (not to scale). (B) Oxidized CNTs aggregated in phosphate buffer, but were dispersed by the peptide. (C) TEM images of peptide with or without nanocarbons in the alkaline buffer. White, dotted lines trace the lacey carbon grid; yellow, dotted lines trace the edges of CNT and CNH surface.

TGA, corresponding to $2.5 \pm 0.2 \mathrm{mmol} \mathrm{COOH} / \mathrm{g}$ for a weight loss of $c a .10 \%$ at $600{ }^{\circ} \mathrm{C}$ (see Figure S7). Oxidation served also as a purification strategy, and each nanocarbon was characterized by Raman spectroscopy and TEM, which confirmed that the structure of the nanocarbons was preserved in all cases (see Figure S7).

Despite the good water dispersibility of the oxidized nanomaterials, CNTs visibly aggregated in the phosphate buffer used to prepare hydrogels. Fortunately, the amphiphilic nature of the tripeptide allowed its use as a CNT dispersant, leading to homogeneous systems when both were added to the alkaline buffer at $\mathrm{pH} 12$ (Figure 3B). The same protocol was applied to $\mathrm{GO}$ and $\mathrm{CNH}$, which showed less aggregation and 
were also better dispersed in the presence of the peptide (Figure S8). TEM images revealed coating of the nanocarbons by the peptide prior to self-assembly; in particular, complete coating was evident for CNTs, while both coated and bare $\mathrm{CNHs}$ could be seen (Figure 3C and Figures S9-S12).

Upon lowering of the $\mathrm{pH}$ to neutral, self-supportive hydrogels were obtained in all cases with a high content of nanocarbon of up to $40 \% \mathrm{w} / \mathrm{w}$ relative to the peptide (Figure 4A). Such high loading suggested a positive interaction with the peptide, since addition of a nanocarbon component (i.e., carbon nanodots) was shown to disrupt gelation of the tripeptide enantiomer at much lower amounts (i.e., $1 \% \mathrm{w} / \mathrm{w}$ at analogous

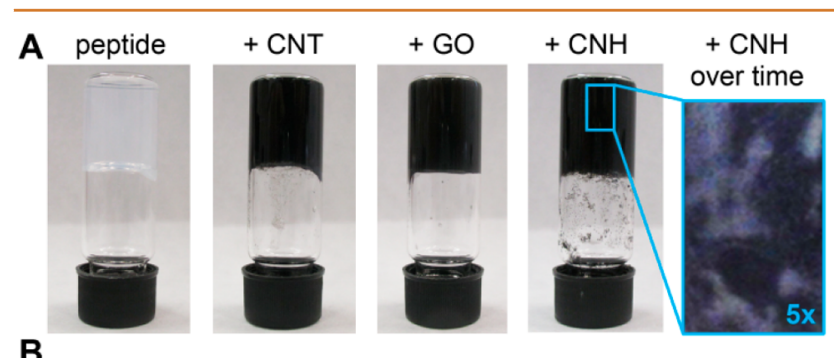

B

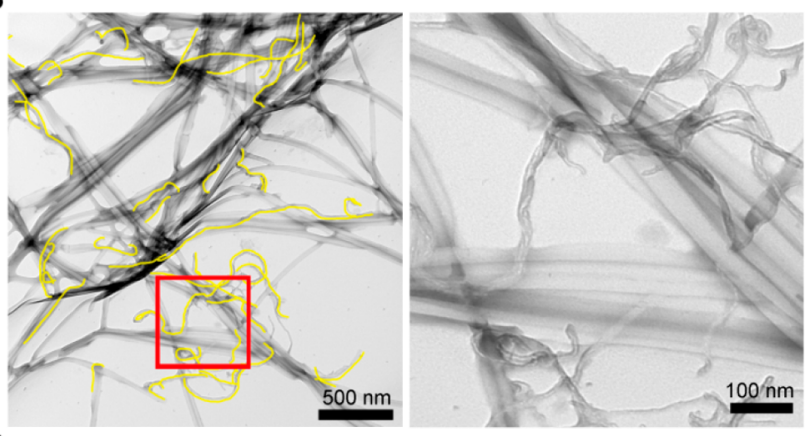

C

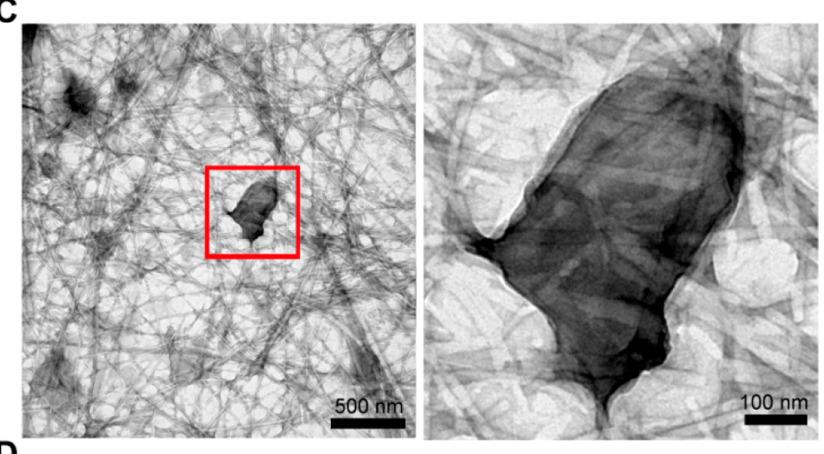

D

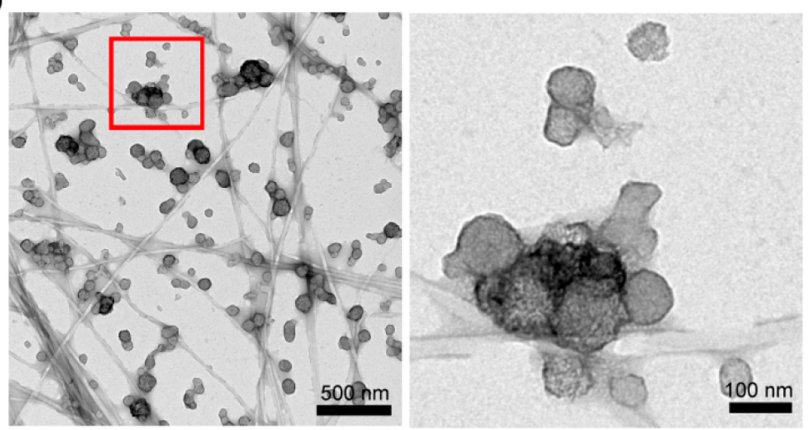

Figure 4. (A) Photographs of self-supportive hydrogels and magnification showing segregation occurring for the CNH-peptide system (inset). (B-D) TEM micrographs at low (left) and high (right) magnification of peptide hydrogels containing CNTs (B), GO (C), or CNHs (D). CNTs are traced in yellow in (B). Red squares indicate the magnified area shown on the right. conditions). ${ }^{27}$ However, within a few hours, the sample containing $\mathrm{CNH}$ s displayed clear signs of nanocarbon segregation from the hydrogel (Figure 4A, inset). TEM micrographs of the hydrogels (Figure 4B-D) confirmed presence of peptide fibers interacting with individualized nanocarbon structures. Only in the case of $\mathrm{CNH}$, nanocarbon clusters were also seen, in agreement with visual observations. In terms of morphology, it is intuitive that elongated peptide fibers interacted and associated with elongated CNTs or the flat surface of GO, while self-association was favored in the case of round and rough $\mathrm{CNHs}$. In particular, TEM micrographs revealed curved CNTs bridging between, and running along, peptide fibers oriented at different angles, suggesting a more effective interaction between peptide fibers and this nanocarbon of analogous anisotropic morphology. In the presence of nanocarbons, peptide fibrils did not vary in diameter (see Table S1), and the mesh size of hydrogel networks was estimated to be $10-15 \mathrm{~nm}$ for all fresh samples using rheology (Table S2). ${ }^{28,29}$ However, mature fiber diameter and bundling over $24 \mathrm{~h}$ was significantly reduced, especially in the case of CNTs and GO, once again suggesting that $\mathrm{CNH}$ interacted less with the peptide (see Figures S14-S17 and TableS1).

Kinetics of assembly were monitored by oscillatory rheology, which confirmed only minor changes in the case of GO and $\mathrm{CNH}$, both of which slowed down supramolecular organization, while CNTs did not (see Figure S18). As expected, presence of the nanocarbons led to stiffer materials in all cases, with an increase of elastic modulus $G^{\prime}$ (i.e., $5-7 \mathrm{kPa}$ for GO and $\mathrm{CNT}$, and $3 \mathrm{kPa}$ for $\mathrm{CNH}$ after $30 \mathrm{~min}$ of self-assembly), relative to the peptide alone (i.e., $2 \mathrm{kPa}$ ), see Table S3. When the nanocarbon loading was decreased 10-fold (i.e., $0.1 \mathrm{mg}$ $\mathrm{mL}^{-1}$ or $0.01 \% \mathrm{w} / \mathrm{v}$, see Supporting Information), material stiffening was still achieved in all cases, and it indicated a qualitative, nonlinear effect (see Figures S19-S20).

Nanocarbons are well-known for their resilience, thus it was expected that their presence would increase hydrogel resistance to applied stresses. Stress sweeps were performed to evaluate this resistance that is directly related to the amplitude of the hydrogel linear viscoelastic zone $\left(G^{\prime}\right.$ and $G^{\prime \prime}$ independence on the applied stress). The material stability was improved, especially in the case of hydrogels containing CNTs. Interestingly, comparison of low versus high nanocarbon content revealed further enhancement in gel stability in the case of CNTs and GO, but not CNH (see Figure S19).

Self-healing behavior was then tested by applying $30 \mathrm{~s}$ pulses of increasing stress (i.e., 50, 100, 150,200, and $250 \mathrm{~Pa}$ ) at $5 \mathrm{~min}$ intervals to allow for recovery (Figure 5). The peptide hydrogel suffered a considerable loss in both moduli already when stressed at $50 \mathrm{~Pa}$, although the gel state was maintained (i.e., $\mathrm{G}^{\prime}$ $\left.>G^{\prime \prime}\right)$. The next pulse at $100 \mathrm{~Pa}$ led to an irreversible transition to a viscous solution (i.e., $G^{\prime \prime}>G^{\prime}$ ). Hydrogels containing GO or $\mathrm{CNH}$ were irreversibly converted to solutions at the third pulse (i.e., $150 \mathrm{~Pa}$ ). By contrast, samples with CNTs maintained their hydrogel nature up to $200 \mathrm{~Pa}$, and, most notably, after the gel-to-sol transition, the hydrogel state was quickly recovered (i.e., $\left.G^{\prime}>G^{\prime \prime}\right)$. Acquisition of self-healing properties was confirmed also for samples with a 10 -fold decrease in CNT content, suggesting once again a qualitative effect upon addition of this nanocarbon (see Figure S21). We propose that the favorable interaction between peptide fibrils and CNTs, both anisotropic structures of elongated morphology and comparable size, plays a key role in the self-healing process that features CNTs connecting different fibers with each other. Fresh 

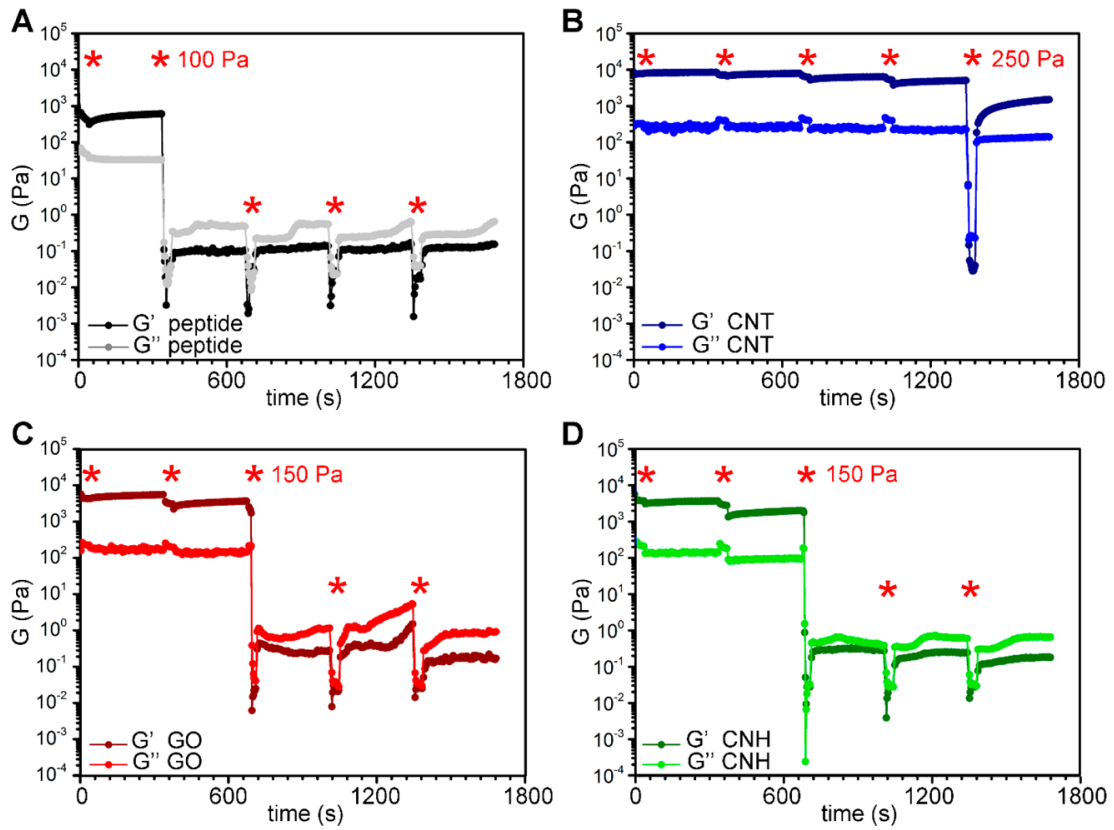

Figure 5. Stress-recovery tests for peptide hydrogel (A), and nanocarbon-peptide hydrogels containing CNTs (B), GO (C), or CNH (D).
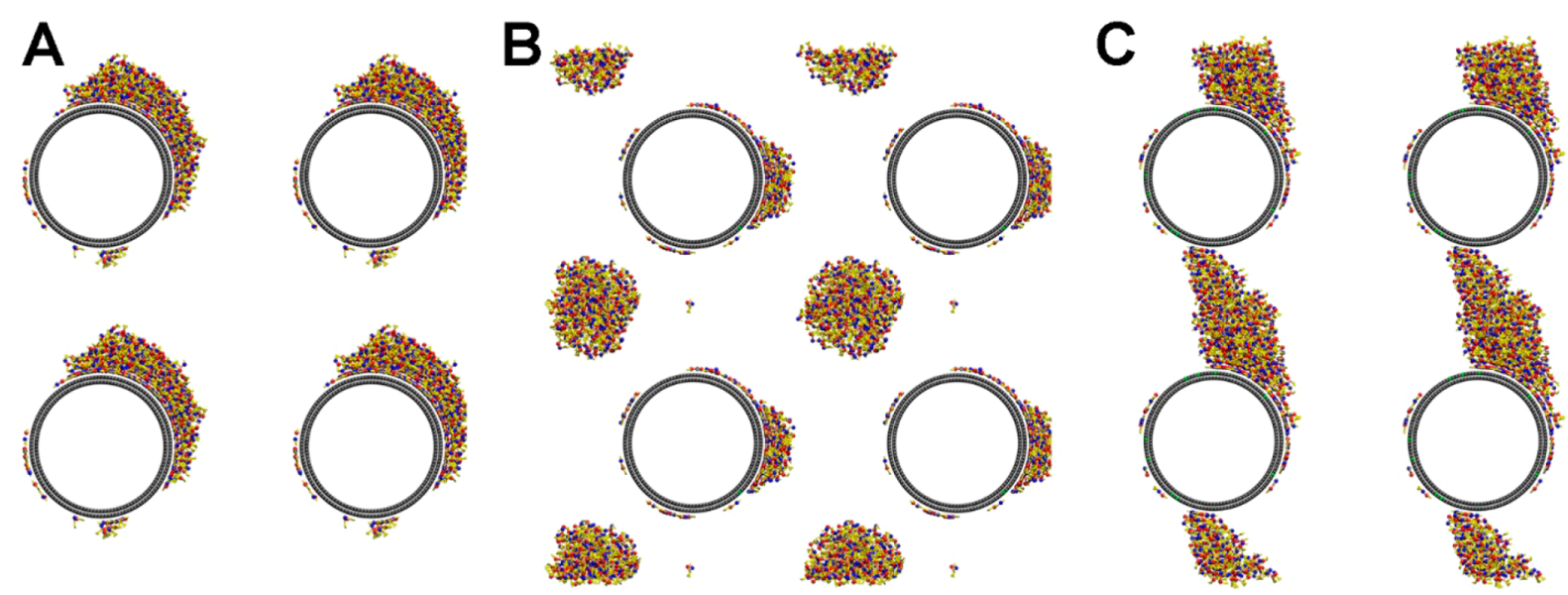

Figure 6. MD of peptide with CNT under self-assembly conditions were run for $20 \mathrm{M}$ steps (600 ns nominal simulation time). (A) Pristine CNT surface covered by peptide. (B) $1 \% \mathrm{w} / \mathrm{w}$ oxidized CNT partially covered by peptide as well as stand-alone peptide aggregate. (C) $10 \% \mathrm{w} /$ w oxidized CNT with peptide aggregate connecting CNTs. Four periodic boxes in the direction perpendicular to the tube axis are represented.

samples imaged during the initial stages of self-assembly displayed $10 \mathrm{~nm}$-wide fibrils that are almost undistinguishable from CNTs (see Figures S22-S23).

Peptide-Nanocarbon Interaction. To better understand the nature of peptide-nanocarbon interaction, a number of analyses were performed. Raman spectroscopy did not provide useful insights, due to the nanocarbon profile dominating the spectra and masking peptide signals, even when CNT content was reduced 10-fold (see Figure S24). Peptide conformation was thus probed both in the gel and sol states by CD and ATRIR (see Figures S25-S26). In solution, no major change was noted upon addition of each nanocarbon, except for significant IR peak broadening in the amide region for the $\mathrm{CNH}$ sample. In the gel state, IR spectra of the amide I region were compatible with $\beta$-sheet organization (i.e., peak at $1637 \mathrm{~cm}^{-1}$ in the amide I region) and displayed no significant difference upon addition of CNTs. By contrast, amide signal broadening and appearance of a shoulder was noted for $\mathrm{GO}$ and $\mathrm{CNH}$, suggesting more supramolecular disorder for the peptide in these samples. Overall, we can conclude that peptide organization was better preserved in the case of addition of CNTs, relative to the other nanocarbons.

It is well-known that nanocarbon curvature and morphology plays an important role in the conformation of adsorbed peptides and proteins, which may orient differently relative to their native state to maximize interaction with the $\mathrm{sp}^{2}$ lattice. To shed further light on the effect of curvature and morphology, SWCNTs were also tested for the preparation of supramolecular hydrogels with the peptide ${ }^{\mathrm{L}} \mathrm{Leu}-{ }^{\mathrm{D}} \mathrm{Phe}-{ }^{\mathrm{D}}$ Phe. SWCNTs are notably more difficult to manipulate than MWCNTs, due to increased propensity toward aggregation. Even highly oxidized SWCNTs (i.e., $18 \%$ wt. loss at $600{ }^{\circ} \mathrm{C}$ by TGA analysis) were not dispersible in the phosphate buffer. In contrast with MWCNTs, SWCNTs dispersion did not improve after addition of the peptide, not even upon prolonged ultrasonication (e.g., $3 \mathrm{~h}$ as opposed to $10-15 \mathrm{~min}$ required for the other nanocarbons). 
It is thus plausible that peptides preferentially adsorbed on the $10 \mathrm{~nm}$-wide MWCNTs relative to the $1 \mathrm{~nm}$-wide SWNCTs, in agreement with recent literature observations for polypeptides and proteins. When exposed to protein-rich samples, SWCNTs and MWCNTs of diameter $<10 \mathrm{~nm}$ virtually bound no proteins, while MWCNTs of diameter $\geq 10 \mathrm{~nm}$ bound them in large amounts. ${ }^{30-32}$ Interestingly, these were mainly filamentous or filament-forming proteins, or proteins that bind filamentous proteins, suggesting an elongated shape as a relevant parameter to determine affinity between the two elements. This concept had already been introduced, since CNTs were envisaged as microtubule biomimetics in light of the striking similarities in shape and size between the two structures. ${ }^{33}$ Microtubules are dynamic systems composed of bundles of protofilaments formed by tubulin protein building blocks, which continuously assemble and disassemble. A population of 5-15 nm-wide MWCNTs demonstrated to enhance and stabilize microtubule polymerization, by acting as tubulin nucleation templates and favoring lateral association with, and between, protofilaments. A net result was the observation of tubulin reassembly after microtubule disassembly in the presence of MWCNTs. ${ }^{34} \mathrm{We}$ thus propose a similar mechanism takes place when MWCNTs interact with the self-assembling tripeptide used in this study.

Molecular Dynamics of Peptide-CNT System. In silico investigation of the tripeptide-CNT system under self-assembly conditions was performed using $10 \mathrm{~nm}$-wide DWCNT models either pristine or oxidized (at $1 \%$ to represent low-level of oxidation or $10 \%$ to represent high level of oxidation). Molecular dynamics (MD) showed that in all cases the peptide adsorbed onto the CNT surface. Importantly, the tripeptide spontaneously aggregated in water very rapidly into one or more large assemblies, while the deposition on the tube was much slower and after $20 \mathrm{M}$ MD steps with $600 \mathrm{~ns}$ of nominal simulation time, the system was not equilibrated (see Figures S27 and S28). Figure 6 shows, in fact, three different scenarios. All tripeptides were adsorbed on the pristine CNT (Figure 6a), leading to full adsorption but not complete coverage of the CNT surface. In the case of $1 \%$ functionalized CNTs, spherical peptide agglomerates were dispersed in water, and reduced peptide adsorption occurred onto the CNT (Figure 6b). Notably, in the case of $10 \%$ oxidized CNT, a peptide fiber formed to connect neighboring CNTs and spanning a $8.5 \mathrm{~nm}$ distance (Figure 6c), in agreement with TEM observations.

Importantly, these results indicate that, under self-assembly conditions, peptide self-association is notably faster than peptide-CNT binding, and this explains why CNTs do not hamper fiber formation, but rather favor the bridging between peptide fibers, thus yielding a more interconnected network, hence a more stable material. In our experimental protocol, peptide adsorption onto the CNTs occurs without interference from the competing process of peptide self-assembly, because it is carried out at alkaline conditions, where peptides are in anionic form and repel each other. Once the $\mathrm{pH}$ is lowered to neutral to trigger self-assembly of zwitterions, peptide selfassociation is favored and the hydrogel forms. If the peptide gel network is mechanically disrupted under applied stress, peptide-coated CNTs will interact with peptide fibers as shown in Figure 6C and template network reorganization in a similar manner as observed for microtubules.

\section{CONCLUSIONS}

This work reports minimal systems composed of a simple unprotected tripeptide and oxidized nanocarbons capable of forming supramolecular hydrogels at physiological conditions. Favorable interaction between the two amphiphilic components in an aqueous environment allowed to obtain self-supportive hydrogels with a nanocarbon content as high as $40 \% \mathrm{w} / \mathrm{w}$ relative to the peptide. Three different carbon nanostructures were tested, and their comparison highlighted nanostructure morphology as a key factor in the determination of supramolecular behavior. In particular, carbon nanohorns displayed a tendency toward self-aggregation that negatively affected the homogeneity of the hydrogel. By contrast, GO and CNTs showed good interfacing with peptide nanofibrils, leading to homogeneous hydrogel networks of enhanced viscoelastic properties relative to the peptide alone (i.e., increased moduli and resistance against applied stress).

Importantly, self-healing ability was acquired exclusively upon inclusion of CNTs into the system. In silico and experimental data suggested that the peptide slowly adsorbed onto the CNT surface, effectively creating a peptide depot that favored the interconnectivity between peptide fibrils and nanotubes, both of which are nanostructures of comparable elongated morphology and size. Peptide adsorption onto the CNT surface was not accompanied by significant changes in peptide conformation, and it slowly occurred in solution prior to self-assembly, allowing CNT dispersion in the buffer. Subsequently, a $\mathrm{pH}$ change from alkaline to neutral triggered peptide rapid assembly into a fibrillary network that included CNTs as bridging elements to reinforce the system. We thus explain the self-healing ability, thanks to peptide-covered CNTs that template reassembly of the 3D supramolecular network in a similar fashion as reported for CNTs and microtubules. Overall, this study revealed an unprotected tripeptide as a minimalistic CNT dispersing agent in aqueous buffer and analogous nanostructure morphology as a key element for the successful design of supramolecular hybrid systems based on chemical components as different as peptides and nanocarbons.

\section{MATERIALS AND METHODS}

Chemicals. Elicarb MWCNTs (ref PR0940, batch 71967/35, purity $70-90 \%$ ) and Elicarb Premium grade graphene powder (ref SP8073P, batch L4002B, 6.6 layers average thickness, $>4 \%$ organic residue and $>4 \%$ oxide residue) were kindly supplied by Thomas Swan and Co. Ltd. CNHs were purchased at Carbonium s.r.l. Two chlorotrityl chloride resin, O-benzotriazole- $N, N, N, N^{\prime}$-tetramethyluronium-hexafluoro-phosphate (HBTU), and the Fmoc-protected amino acids were purchased from GL Biochem (Shanghai) Ltd. (Shanghai, China). Solvents and chemicals were purchased from Sigma-Aldrich (Milan, Italy). All chemicals were used as received.

Peptide Synthesis. ${ }^{\mathrm{L}} \mathrm{Leu}-{ }^{\mathrm{D}} \mathrm{Phe}-{ }^{\mathrm{D}} \mathrm{Phe}$ was synthesized following Fmoc-based SPPS under dry and inert atmosphere. Briefly, the swelling of the resin (2-chlorotrytil chloride, $5 \mathrm{~g}$ ) was done in dichloromethane $(20 \mathrm{~mL})$. Then $\mathrm{SOCl}_{2}(0.4 \mathrm{~mL})$ was added, and the reaction was stirred under an Ar flow for $1 \mathrm{~h}$. After that, the resin was washed with DMF $(3 \times 15 \mathrm{~mL})$ and dicloromethane $(3 \times 15 \mathrm{~mL})$. Next, a solution of Fmoc- ${ }^{\mathrm{D}} \mathrm{Phe}-\mathrm{OH}(2 \mathrm{~g}, 5.2 \mathrm{mmol})$, DIPEA $(4.5 \mathrm{~mL}$, $25.9 \mathrm{mmol}$ ) in DMF/dichloromethane $3 / 1$ was added to the reactor, and the reaction was stirred for $1.5 \mathrm{~h}$. Then, $\mathrm{MeOH}(1 \mathrm{~mL})$ was added before washing the reaction with $\operatorname{DMF}(3 \times 15 \mathrm{~mL})$ and dicloromethane $(3 \times 15 \mathrm{~mL})$. For the deprotection, piperidine $25 \%$ in DMF $(5 \mathrm{~mL})$ was added to the reactor and was stirred at room temperature for $20 \mathrm{~min}$. The reaction mixture was washed with DMF and dichloromethane. For the first coupling, Fmoc- ${ }^{\mathrm{D}} \mathrm{Phe}-\mathrm{OH}$ (2.905 g, $7.5 \mathrm{mmol})$, DIPEA $1 \mathrm{M}$ in DMF (6 mL), and HBTU (2.275 g, 6 
mmol) in DMF were ultrasonicated until the solution was clear, the mixture was added to the reactor, and the coupling was stirred at room temperature for $1 \mathrm{~h}$. Then, the crude was washed and deprotected as in the previous step. The coupling and deprotection of the last amino acid were done exactly the same way as the first coupling, but adding Fmoc- ${ }^{\mathrm{L}} \mathrm{Leu}-\mathrm{OH}(2.650 \mathrm{~g}, 7.5 \mathrm{mmol})$ instead of Fmoc- ${ }^{\mathrm{D}} \mathrm{Phe}-\mathrm{OH}$. Eventually, a solution of TFA/dichloromethane $/ \mathrm{H}_{2} \mathrm{O} /$ TIPS 49/49/1/ $1(25 \mathrm{~mL})$ was added to cleave the peptide from the resin. After $2 \mathrm{~h}$ of cleavage the solution was drained from the reactor, and the solvent was evaporated under an air stream. The crude was purified by reversedphase HPLC (Waters). The HPLC was equipped with a semipreparative column C18 and a photodetector at 214 and $254 \mathrm{~nm}$. The solvent was a mixture of $\mathrm{CH}_{3} \mathrm{CN}: \mathrm{H}_{2} \mathrm{O}$ following the program: $t=0-2$ $\min , 25 \% \mathrm{CH}_{3} \mathrm{CN}, t=25 \mathrm{~min}, 95 \% \mathrm{CH}_{3} \mathrm{CN}\left(t_{\mathrm{R}}=10-11 \mathrm{~min}\right) ; 0.1 \%$ trifluoroacetic acid was added to both solvents.

Oxidation of MWCNTs. Four ml of $\mathrm{HNO}_{3}(69 \%)$ and $12 \mathrm{~mL}$ of $\mathrm{H}_{2} \mathrm{SO}_{4}(95 \%)$ were mixed in a round-bottom flask. Then, $100 \mathrm{mg}$ of pristine MWNTs was added on top. The resulting mixture was sonicated for $5 \mathrm{~h}$ at room temperature. After that, the reaction was quenched with cold water $(200 \mathrm{~mL})$. The crude was filtered through Millipore membrane (JHWP, $0.45 \mu \mathrm{m}$ ) and washed with deionized water until neutralization of the washings. The black powder was finally washed with $\mathrm{MeOH}$ and dried with $\mathrm{Et}_{2} \mathrm{O}$ affording $99 \mathrm{mg}$ of oxidized MWCNTs.

Oxidation of G. GO was prepared following a modified version of the Hummer's method. ${ }^{35,36}$ In a $100 \mathrm{~mL}$ round-bottomed flask containing $\mathrm{K}_{2} \mathrm{~S}_{2} \mathrm{O}_{8}(200 \mathrm{mg}, 0.37 \mathrm{mmol}), \mathrm{P}_{2} \mathrm{O}_{5}(100 \mathrm{mg}, 0.35 \mathrm{mmol})$, and $\mathrm{H}_{2} \mathrm{SO}_{4}(10 \mathrm{~mL})$, pristine $\mathrm{G}(200 \mathrm{mg})$ was added. The reaction was stirred at $80{ }^{\circ} \mathrm{C}$ for $4 \mathrm{~h}$. The crude was cooled down, diluted with deionized water $(50 \mathrm{~mL})$, filtered through Millipore membrane (JHWP, $0.45 \mu \mathrm{m}$ ), and washed with deionized water until neutralization of the washings. The black powder collected from the Millipore membrane was transferred into a round-bottom flask, and $\mathrm{KMnO}_{4}(100 \mathrm{mg}, 0.63 \mathrm{mmol})$ and $\mathrm{H}_{2} \mathrm{SO}_{4}(20 \mathrm{~mL})$ were added at 0 ${ }^{\circ} \mathrm{C}$. The mixture was stirred at $35{ }^{\circ} \mathrm{C}$ for $2 \mathrm{~h}$. After that, deionized water $(20 \mathrm{~mL})$ and $\mathrm{H}_{2} \mathrm{O}_{2} 30 \%(2.4 \mathrm{~mL})$ were added, and the reaction was stirred for $15 \mathrm{~min}$. The crude was filtered through Millipore membrane (JHWP, $0.45 \mu \mathrm{m})$ and washed with $\mathrm{HCl} 1 \mathrm{M}(100 \mathrm{~mL})$ and deionized water until neutralization of the washings. Eventually the black powder was washed with $\mathrm{MeOH}$ and dried with $\mathrm{Et}_{2} \mathrm{O}$ affording $217 \mathrm{mg}$ of GO.

Oxidation of CNHs. Pristine CNHs (100 mg) were sonicated in $100 \mathrm{~mL}$ of $\mathrm{HNO}_{3}$ (69\%) for $15 \mathrm{~min}$. The resulting dispersion was stirred for $3 \mathrm{~h}$ at $35^{\circ} \mathrm{C}$. Cold water $(200 \mathrm{~mL})$ was then added to the reaction, and the crude was filtered through a Millipore membrane (JHWP, $0.45 \mu \mathrm{m}$ ) and washed with deionized water until neutralization of the washings. The black powder was finally washed with $\mathrm{MeOH}$ and dried with $\mathrm{Et}_{2} \mathrm{O}$ affording $99 \mathrm{mg}$ of oxidized CNHs.

Hydrogel Formation. For the peptide hydrogel, $5 \mathrm{mg}$ of ${ }^{\mathrm{L}} \mathrm{Leu}-{ }^{\mathrm{D}} \mathrm{Phe}-{ }^{\mathrm{D}} \mathrm{Phe}$ was ultrasonicated in $1 \mathrm{~mL}$ alkaline sodium phosphate buffer $(0.1 \mathrm{M}, \mathrm{pH} 11.8)$ until complete dissolution (i.e. Five min) in a Branson sonicator bath $40 \mathrm{kHz}$ at room temperature. Then, the hydrogel was formed when the $\mathrm{pH}$ of the solution was brought to neutral upon the addition of $1 \mathrm{~mL}$ of mildly acidic sodium phosphate buffer $(0.1 \mathrm{M}, \mathrm{pH} 5.8)$. For the peptide hydrogel containing ox-CNS, $5 \mathrm{mg}$ of ${ }^{\mathrm{L}}$ Leu- ${ }^{\mathrm{D}}$ Phe- ${ }^{\mathrm{D}}$ Phe and $2 \mathrm{mg}$ of ox-CNS were ultrasonicated in $1 \mathrm{~mL}$ alkaline sodium phosphate buffer $(0.1 \mathrm{M}, \mathrm{pH}$ 11.8) until homogeneity (i.e. Fifteen min). Then, the hydrogel was formed when the $\mathrm{pH}$ of the solution was brought to neutral upon addition of $1 \mathrm{~mL}$ of mildly acidic sodium phosphate buffer $(0.1 \mathrm{M}, \mathrm{pH}$ 5.8). For the low ox-CNS content, a stock solution of the peptide (5 $\left.\mathrm{mg} \mathrm{mL} \mathrm{m}^{-1}\right)$ and the corresponding ox-CNS $\left(0.2 \mathrm{mg} \mathrm{mL}^{-1}\right)$ were prepared in the same buffer as outlined above. Then, gels were prepared using $1 \mathrm{~mL}$ from the stock solution and $1 \mathrm{~mL}$ of the acidic sodium phosphate buffer.

Protease Assay. The peptide $(2.0 \mathrm{mg})$ was dissolved with 0.250 $\mathrm{mL}$ DMSO and $4.750 \mathrm{~mL}$ of $50 \mathrm{mM}$ sodium phosphate buffer $(\mathrm{pH}$ 7.5) containing a large excess $(5 \mathrm{mg})$ of proteinase $\mathrm{K}$ from Tritirachium album (Sigma-Aldrich P8044 3-15 U/mg) in $15 \mathrm{~mL}$ Falcon tubes. The tubes were incubated at $37{ }^{\circ} \mathrm{C}, 60 \mathrm{rpm}$, and at various time points $1 \mathrm{~mL}$ samples were taken, added to $0.400 \mathrm{~mL}$ $\mathrm{NaOH} 1 \mathrm{M}$ to stop the reaction, and analyzed by HPLC (Abs $254 \mathrm{~nm}$, same program as described above for peptide purification). Average and standard deviation values $(n=3)$ were calculated and plotted with Excel.

Materials Spectroscopic and Thermogravimetric Characterization. NMR spectra was recorded on a Varian Inova $500 \mathrm{MHz}$ Chemical shifts are reported in ppm using the solvent residual signal as internal reference (DMSO- $d_{6}: \delta \mathrm{H}=2.50 \mathrm{ppm}$ or $\delta \mathrm{C}=39.51 \mathrm{ppm}$ ). ESI-MS spectra were acquired on an Infinity 6120 single quadrupole LC-MS system (Agilent Technologies, Milan, Italy). TGA of approximately $1 \mathrm{mg}$ of each compound was recorded on a TGA Q500 (TA Instruments) under nitrogen, by equilibrating at $100{ }^{\circ} \mathrm{C}$ for $20 \mathrm{~min}$, and following a ramp of $10^{\circ} \mathrm{C} \mathrm{min}^{-1}$ up to $800{ }^{\circ} \mathrm{C}$. Raman spectra were recorded with an Invia Renishaw microspectrometer (50) equipped with $\mathrm{He}-\mathrm{Ne}$ laser at $532 \mathrm{~nm}$. For the oxidized carbon nanomaterials, samples were dispersed in $\mathrm{EtOH}$ and filtrated through a Millipore membrane (JHWP, $0.45 \mu \mathrm{m}$ ). $\mathrm{Et}_{2} \mathrm{O}$ was added to dry the material. Then, a uniform layer of material was transferred to a doublesided scotch tape. At least 10 spectra per sample were collected to check their homogeneity. In the case of the hydrogels, the sample was transferred to a silicon wafer and dried under vacuum before the analysis. For Raman imaging, the samples preparation and the laser were analogous. The laser was focused using the $50 \times$ microscope, and the power was set at $0.25 \mathrm{~mW}$. An area of around $1000 \mu \mathrm{m}^{2}$ was mapped over 3000 points. The exposure time for every point was $1 \mathrm{~s}$. Circular dichroism spectra were acquired on a Jasco J-815 spectropolarimeter equipped with a Peltier temperature control system. Experiments were performed at $25^{\circ} \mathrm{C}$, from 190 to $300 \mathrm{~nm}$, using a $0.1 \mathrm{~mm}$ path length quartz cuvette. ATR-IR measurements were performed in a Varian 660 spectrometer operating at the ATR mode. 128 scans were acquired for every sample with a resolution of 4 $\mathrm{cm}^{-1}$. For the preparation of the samples, a portion of the gel (i.e., 0.5 $\mathrm{mL}$ ) was deposited on top of silicon wafer and was dried under vacuum.

Oscillatory Rheology. Rheological analyses were performed on a stress-controlled rotational rheometer Haake MARS III equipped with a Peltier temperature control system. $60 \mathrm{~mm}$ titanium flat plates were used for all measurements with a gap of $0.345 \mathrm{~mm}$. Time sweeps were performed at $1 \mathrm{~Pa}$ and $1 \mathrm{~Hz}$ for $1 \mathrm{~h}$. Frequency sweeps were recorded at $2 \mathrm{~Pa}$ from 0.1 to $10 \mathrm{~Hz}$. Stress sweeps were performed from $1 \mathrm{~Pa}$ up to gel failure at $1 \mathrm{~Hz}$. For the recovery tests, the gelation was allowed to occur for $30 \mathrm{~min}$ before challenging for $30 \mathrm{~s}$ at increasing stress values (i.e., 50,100,150, 200, $250 \mathrm{~Pa}$ ) with $5 \mathrm{~min}$ intervals for recovery.

TEM and AFM Imaging. For TEM imaging of carbon nanomaterials, a concentrated dispersion of the sample in ethanol was ultrasonicated and then drop-casted on a copper grid (200 mesh, copper, carbon only). After evaporation of the solvent under vacuum, the samples were analyzed with a Philips EM 208 microscope operating at $100 \mathrm{kV}$. For the TEM images of the hydrogels and precursor solutions, a small portion of the gel or the solution (i.e., 20 $\mu \mathrm{L}$ ) was deposited on top of a copper grid (200 mesh, copper, carbon only or lacey carbon). After $30 \mathrm{~s}$ of contact, water was drawn from the sample. Then, the grid was deposited on top of a drop of $2 \%$ aqueous potassium phosphotungstate at $\mathrm{pH} 7.2$ for $30 \mathrm{~s}$, and the grid was dried under vacuum before its visualization on a TEM FEI Tecnai G2 operating at $100 \mathrm{kV}$. For AFM imaging, samples were placed on a clean mica surface. Atomic force microscopy (AFM) measurements were performed using a Nanoscope $\mathrm{V}$ microscope (Digital Instruments Metrology Group, model MMAFMLN) in tapping mode at room temperature in air, using standard $\mu$ masch SPM probe (HQ:NSC15/ AIBS) with tip height $12-18 \mu \mathrm{m}$ and cone angle $<40^{\circ}$ (Resonant frequency $325 \mathrm{kHz}$, force constant of $\sim 40 \mathrm{~N} \mathrm{~m}^{-1}$ ). Image analysis was performed with Gwyddion software.

Computer Modeling. Coarse-grained molecular dynamics (CG$\mathrm{MD}$ ) simulations with the Martini coarse-grained force field, v2.2, ${ }^{37}$ were performed with the GROMACS 5.1.4 simulation suite. ${ }^{38}$ In order to increase computational efficiency, the MWCNT was modeled by a DWCNT built by two concentric nanotubes: $(128,0)$ and $(119,0),{ }^{39}$ 
since the bulk of the intermolecular interaction with the adsorbates and solvent arises from the two outermost layers of the MWCNT. ${ }^{40}$

Two oxidized moieties were considered: epoxide and alcohol groups. In the CG CNT model, CG-CNT, four pristine carbon atoms were represented by the $\mathrm{SC} 4$ bead, while the epoxide functional group $(\mathrm{C}-\mathrm{O}-\mathrm{C})$ and alcohol functional group $(\mathrm{C} 2-\mathrm{OH})$ were represented by the SN0 and SP1 beads, respectively. The CG-CNT model was generated with a python code written for this purpose. For the oxidized CG-CNT systems, $1 \%$ and $10 \%$ SN0/SP1 beads were located randomly on the surface of the outermost CNT. The simulations were performed in an orthogonal $19.5 \times 19.5 \times 11.9 \mathrm{~nm}^{3}$ periodic box dimensions containing: an $11.9 \mathrm{~nm}$ periodic CNT, 430 peptides, and 26170 water beads. An unpolarized water model was used in all simulations due to improved computational efficiency after a model of pristine carbon nanotubes in solution yielded similar results with polarized and unpolarized CG water models. CG-MD simulations were run at $320 \mathrm{~K}$ after energy minimization and equilibration with semi-isotropic NPT Berendsen rescaling. Production runs were computed with stochastic velocity rescaling in the NVT ensemble with a time step of $30 \mathrm{fs}$. The CG-CNT beads were frozen during all the simulations.

\section{ASSOCIATED CONTENT}

\section{S Supporting Information}

The Supporting Information is available free of charge on the ACS Publications website at DOI: 10.1021/acsnano.8b01182.

Peptide spectroscopic data, in silico and experimental characterization of peptide-nanocarbon systems both in gel and sol (PDF)

\section{AUTHOR INFORMATION}

\section{Corresponding Author}

*E-mail: smarchesan@units.it.

\section{ORCID}

Daniel Iglesias: 0000-0002-1998-0518

Michele Melchionna: 0000-0001-9813-9753

Mario Grassi: 0000-0002-3532-3200

Maurizio Prato: 0000-0002-8869-8612

Silvia Marchesan: 0000-0001-6089-3873

\section{Notes}

The authors declare no competing financial interest.

\section{ACKNOWLEDGMENTS}

D.I. and S.M. would like to acknowledge funding from the Italian Ministry of Education and Research, through the PRIN Giovani 2015 program (grant no. 2015TWP83Z). This study was supported by the European Union H2020 Program under grant agreements no. 696656-Graphene Flagship Core1 and no. 785219-Graphene Flagship Core2, and by COST (European Cooperation in Science and Technology), Cost Action CA15107 (MultiComp), through an STSM grant. M.M.F. would like to acknowledge funding from CICECO-Aveiro Institute of Materials, POCI-01-0145-FEDER-007679 (FCT ref UID/CTM/50011/2013). The authors would like to acknowledge M. Bisiacchi (University of Trieste, Department of Chemical and Pharmaceutical Sciences) for technical assistance.

\section{REFERENCES}

(1) Du, X.; Zhou, J.; Shi, J.; Xu, B. Supramolecular Hydrogelators and Hydrogels: From Soft Matter to Molecular Biomaterials. Chem. Rev. 2015, 115, 13165-13307.

(2) Adams, D. J. Dipeptide and Tripeptide Conjugates as LowMolecular-Weight Hydrogelators. Macromol. Biosci. 2011, 11, 160173.
(3) Ung, P.; Winkler, D. A. Tripeptide Motifs in Biology: Targets for Peptidomimetic Design. J. Med. Chem. 2011, 54, 1111-1125.

(4) Wang, H.; Feng, Z.; Xu, B. Bioinspired Assembly of Small Molecules in Cell Milieu. Chem. Soc. Rev. 2017, 46, 2421-2436.

(5) Luo, Z.; Wu, Q.; Yang, C.; Wang, H.; He, T.; Wang, Y.; Wang, Z.; Chen, H.; Li, X.; Gong, C.; Yang, Z. A Powerful CD8 ${ }^{+}$T-Cell Stimulating D-Tetra-Peptide Hydrogel as a Very Promising Vaccine Adjuvant. Adv. Mater. 2017, 29, 1601776.

(6) Fleming, S.; Ulijn, R. V. Design of Nanostructures Based on Aromatic Peptide Amphiphiles. Chem. Soc. Rev. 2014, 43, 8150-8177.

(7) Martin, A. D.; Wojciechowski, J. P.; Warren, H.; in het Panhuis, M.; Thordarson, P. Effect of Heterocyclic Capping Groups on the SelfAssembly of a Dipeptide Hydrogel. Soft Matter 2016, 12, 2700-2707.

(8) Frederix, P. W.; Scott, G. G.; Abul-Haija, Y. M.; Kalafatovic, D.; Pappas, C. G.; Javid, N.; Hunt, N. T.; Ulijn, R. V.; Tuttle, T. Exploring the Sequence Space for (Tri-)peptide Self-Assembly to Design and Discover New Hydrogels. Nat. Chem. 2015, 7, 30-37.

(9) Yan, X.; Zhu, P.; Li, J. Self-Assembly and Application of Diphenylalanine-Based Nanostructures. Chem. Soc. Rev. 2010, 39, $1877-1890$

(10) Marchesan, S.; Qu, Y.; Waddington, L. J.; Easton, C. D.; Glattauer, V.; Lithgow, T. J.; McLean, K. M.; Forsythe, J. S.; Hartley, P. G. Self-Assembly of Ciprofloxacin and a Tripeptide into an Antimicrobial Nanostructured Hydrogel. Biomaterials 2013, 34, 3678-3687.

(11) Merino, S.; Martín, C.; Kostarelos, K.; Prato, M.; Vázquez, E. Nanocomposite Hydrogels: 3D Polymer-Nanoparticle Synergies for On-Demand Drug Delivery. ACS Nano 2015, 9, 4686-4697.

(12) Cha, C.; Shin, S. R.; Annabi, N.; Dokmeci, M. R.; Khademhosseini, A. Carbon-Based Nanomaterials: Multifunctional Materials for Biomedical Engineering. ACS Nano 2013, 7, 2891-2897.

(13) Iglesias, D.; Bosi, S.; Melchionna, M.; Da Ros, T.; Marchesan, S. The Glitter of Carbon Nanostructures in Hybrid/Composite Hydrogels for Medicinal Use. Curr. Top. Med. Chem. (Sharjah, United Arab Emirates) 2016, 16, 1976-1989.

(14) Marchesan, S.; Melchionna, M.; Prato, M. Wire Up on Carbon Nanostructures! How To Play a Winning Game. ACS Nano 2015, 9, 9441-9450.

(15) Calvaresi, M.; Zerbetto, F. The Devil and Holy Water: Protein and Carbon Nanotube Hybrids. Acc. Chem. Res. 2013, 46, 2454-2463.

(16) Li, C.; Mezzenga, R. The Interplay Between Carbon Nanomaterials and Amyloid Fibrils in Bio-Nanotechnology. Nanoscale 2013, 5, 6207-6218.

(17) Shin, S. R.; Jung, S. M.; Zalabany, M.; Kim, K.; Zorlutuna, P.; Kim, S. b.; Nikkhah, M.; Khabiry, M.; Azize, M.; Kong, J.; Wan, K.-T.; Palacios, T.; Dokmeci, M. R.; Bae, J.; Tang, X.; Khademhosseini, A. Carbon-Nanotube-Embedded Hydrogel Sheets for Engineering Cardiac Constructs and Bioactuators. ACS Nano 2013, 7, 2369-2380.

(18) Marchesan, S.; Ballerini, L.; Prato, M. Nanomaterials for Stimulating Nerve Growth. Science 2017, 356, 1010-1011.

(19) Roy, S.; Banerjee, A. Functionalized Single Walled Carbon Nanotube Containing Amino Acid Based Hydrogel: a Hybrid Nanomaterial. RSC Adv. 2012, 2, 2105-2111.

(20) Adhikari, B.; Banerjee, A. Short Peptide Based Hydrogels: Incorporation of Graphene into the Hydrogel. Soft Matter 2011, 7, 9259-9266.

(21) Mba, M.; Jiménez, A. I.; Moretto, A. Templating the SelfAssembly of Pristine Carbon Nanostructures in Water. Chem. - Eur. J. 2014, 20, 3888-3893.

(22) Dinesh, B.; Squillaci, M. A.; Menard-Moyon, C.; Samori, P.; Bianco, A. Self-Assembly of Diphenylalanine Backbone Homologues and Their Combination with Functionalized Carbon Nanotubes. Nanoscale 2015, 7, 15873-15879.

(23) Ali-Boucetta, H.; Nunes, A.; Sainz, R.; Herrero, M. A.; Tian, B.; Prato, M.; Bianco, A.; Kostarelos, K. Asbestos-like Pathogenicity of Long Carbon Nanotubes Alleviated by Chemical Functionalization. Angew. Chem., Int. Ed. 2013, 52, 2274-2278.

(24) Marchesan, S.; Styan, K. E.; Easton, C. D.; Waddington, L.; Vargiu, A. V. Higher and Lower Supramolecular Orders for the Design 
of Self-Assembled Heterochiral Tripeptide Hydrogel biomaterials. J. Mater. Chem. B 2015, 3, 8123-8132.

(25) Marchesan, S.; Waddington, L.; Easton, C. D.; Winkler, D. A.; Goodall, L.; Forsythe, J.; Hartley, P. G. Unzipping the Role of Chirality in Nanoscale Self-Assembly of Tripeptide Hydrogels. Nanoscale 2012, 4, 6752-6760.

(26) Lekprasert, B.; Korolkov, V.; Falamas, A.; Chis, V.; Roberts, C. J.; Tendler, S. J.; Notingher, I. Investigations of the Supramolecular Structure of Individual Diphenylalanine Nano- and Microtubes by Polarized Raman Microspectroscopy. Biomacromolecules 2012, 13, 2181-2187.

(27) Cringoli, M. C.; Kralj, S.; Kurbasic, M.; Urban, M.; Marchesan, S. Luminescent Supramolecular Hydrogels from a Tripeptide and Nitrogen-Doped Carbon Nanodots. Beilstein J. Nanotechnol. 2017, 8, $1553-1562$.

(28) Porrelli, D.; Cok, M.; Abrami, M.; Bosi, S.; Prato, M.; Grassi, M.; Paoletti, S.; Donati, I. Evaluation of Concentration and Dispersion of Functionalized Carbon Nanotubes in Aqueous Media by Means of Low Field Nuclear Magnetic Resonance. Carbon 2017, 113, 387-394.

(29) Marizza, P.; Abrami, M.; Keller, S. S.; Posocco, P.; Laurini, E.; Goswami, K.; Skov, A. L.; Boisen, A.; Larobina, D.; Grassi, G.; Grassi, M. Synthesis and Characterization of UV Photocrosslinkable Hydrogels with Poly( $N$-vinyl-2-pyrrolidone): Determination of the Network Mesh Size Distribution. Int. J. Polym. Mater. 2016, 65, 516-525.

(30) Sund, J.; Alenius, H.; Vippola, M.; Savolainen, K.; Puustinen, A. Proteomic Characterization of Engineered Nanomaterial-Protein Interactions in Relation to Surface Reactivity. ACS Nano 2011, 5, 4300-4309.

(31) Cai, X.; Ramalingam, R.; Wong, H. S.; Cheng, J.; Ajuh, P.; Cheng, S. H.; Lam, Y. W. Characterization of Carbon Nanotube Protein Corona by Using Quantitative Proteomics. Nanomedicine (N. Y., NY, U. S.) 2013, 9, 583-593.

(32) Shannahan, J. H.; Brown, J. M.; Chen, R.; Ke, P. C.; Lai, X.; Mitra, S.; Witzmann, F. A. Comparison of Nanotube-Protein Corona Composition in Cell Culture Media. Small 2013, 9, 2171-2181.

(33) Pampaloni, F.; Florin, E.-L. Microtubule Architecture: Inspiration for Novel Carbon Nanotube-Based Biomimetic Materials. Trends Biotechnol. 2008, 26, 302-310.

(34) Rodriguez-Fernandez, L.; Valiente, R.; Gonzalez, J.; Villegas, J. C.; Fanarraga, M. L. Multiwalled Carbon Nanotubes Display Microtubule Biomimetic Properties in Vivo, Enhancing Microtubule Assembly and Stabilization. ACS Nano 2012, 6, 6614-6625.

(35) Poh, H. L.; Sanek, F.; Ambrosi, A.; Zhao, G.; Sofer, Z.; Pumera, M. Graphenes prepared by Staudenmaier, Hofmann and Hummers Methods with Consequent Thermal Exfoliation Exhibit Very Different Electrochemical Properties. Nanoscale 2012, 4, 3515-3522.

(36) Hummers, W. S.; Offeman, R. E. Preparation of Graphitic Oxide. J. Am. Chem. Soc. 1958, 80, 1339-1339.

(37) de Jong, D. H.; Singh, G.; Bennett, W. F. D.; Arnarez, C.; Wassenaar, T. A.; Schäfer, L. V.; Periole, X.; Tieleman, D. P.; Marrink, S. J. Improved Parameters for the Martini Coarse-Grained Protein Force Field. J. Chem. Theory Comput. 2013, 9, 687-697.

(38) Abraham, M. J.; Murtola, T.; Schulz, R.; Páll, S.; Smith, J. C.; Hess, B.; Lindahl, E. GROMACS: High Performance Molecular Simulations Through Multi-Level Parallelism from Laptops to Supercomputers. SoftwareX 2015, 1-2, 19-25.

(39) Bellarosa, L.; Bakalis, E.; Melle-Franco, M.; Zerbetto, F. Interactions in Concentric Carbon Nanotubes: The Radius vs. the Chirality Angle Contributions. Nano Lett. 2006, 6, 1950-1954.

(40) Strutyński, K.; Gomes, J. A. N. F.; Melle-Franco, M. Accuracy of Dispersion Interactions in Semiempirical and Molecular Mechanics Models: The Benzene Dimer Case. J. Phys. Chem. A 2014, 118, 95619567. 